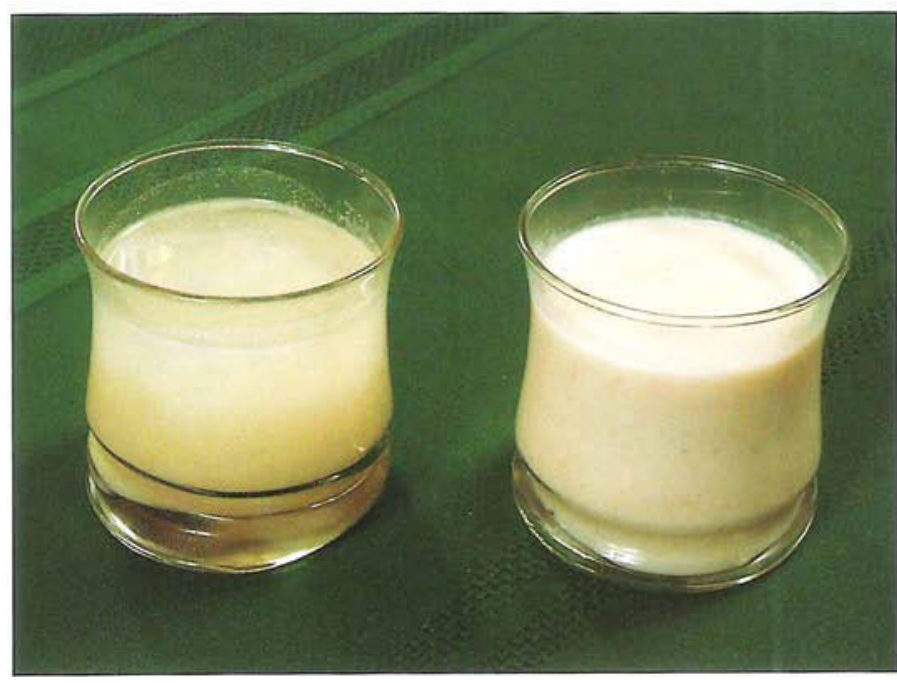

Atole is a traditional milk-based beverage usually prepared with masa (cornmeal), oats, or cornstarch, and served hot.

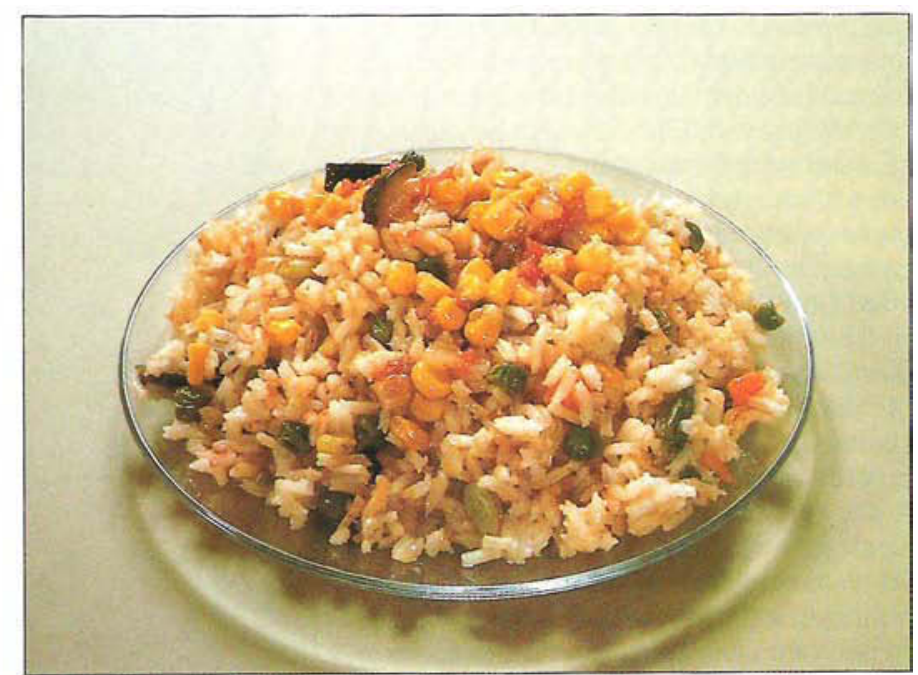

Arroz con verduras (rice with vegetables) is a nutritious dish popular in Latin American countries, but its consumption has decreased significantly among Latinos in California.

\title{
Dietary change among Latinos of Mexican descent in California
}

\author{
Eunice Romero-Gwynn \\ - Douglas Gwynn \ Barbara Turner \\ G Gwendolyn Stanford \\ - Estella West \\ Eunice Williamson $\square$ Louis Grivetti $\square$ Roger McDonald
}

\begin{abstract}
Mexican immigrants to California and their descendants are maintaining some traditional eating patterns as they incorporate many new foods into their diets, a survey found. There have been modest increases in the consumption of milk, vegetables, and fruits. But not all changes are for the best: consumption of fats, sugar, and sliced white bread is up.
\end{abstract}

An increasing proportion of California's food consumers are Latinos of Mexican descent. How this population maintains its traditional eating patterns and incorporates new foods into its diet is the subject of a new survey.

Since pre-columbian times, the traditional Mexican diet has included corn, chili peppers, beans, squash, and many other fruits and vegetables, as well as meat from wild animals. With the Spanish introduction of cattle to the New World, consumption of milk, cheese, and beef began. Wheat and bread-making, also introduced by the Spanish, were later encouraged by the French. Other Europeans introduced rice, pastas, oils, and sugar. Today, the typical diet in Mexico reflects a blend of native foods and influences from other countries. Here, we evaluate the diets of immigrants from Mexico and MexicanAmericans living in the United States.

\section{The sample}

The survey sample was selected from the Expanded Food and Nutrition Education Program enrollment forms from six California counties. Chosen for the study were 165 immigrants from Mexico and 101 Mexican-Americans who were born in the United States. All respondents were adult low-income women. The average age was 34 , and the average number of years of formal education was 7. Eight trained interviewers, all of Mexican descent and knowledgeable about Mexican food practices and terminology, conducted the interviews.

In addition to demographic characteristics, we assessed the frequency with which immigrants consumed particular foods in Mexico before immigration, the frequency with which they consumed those same foods after immigration to the United States, and the frequency with which firstgeneration Mexican-Americans consumed those foods. More than 100 traditional Mexican foods and dishes and non- traditional foods characteristic of the U.S. diet were identified. Consumption patterns were identified over different time intervals, ranging from several times a day to once a year; this article, however, concentrates on the primary core diet of foods consumed 2 to 7 days a week.

\section{Findings}

With immigration to the United States, major changes occurred in the participants' diets. Consumption of many traditional dishes decreased with acculturation. A few foods and dishes remained as staples. With acculturation, many new foods were added to diets.

Milk and milk products. More cheese than milk was consumed both in Mexico and in the United States. Consumption of cheese in Mexico 2 to 7 days a week was reported by $85 \%$ of the respondents and in the United States by $91 \%$. Contrary to common belief among health professionals, milk was widely consumed by the Mexican immigrants and Mexican-Americans in our sample. Seventy-eight percent of immigrant respondents reported having consumed milk almost every day in Mexico; in the United States, their frequency of consumption increased to $85 \%$. Mexican-Americans had a slightly higher frequency of milk consumption: $88 \%$ of 


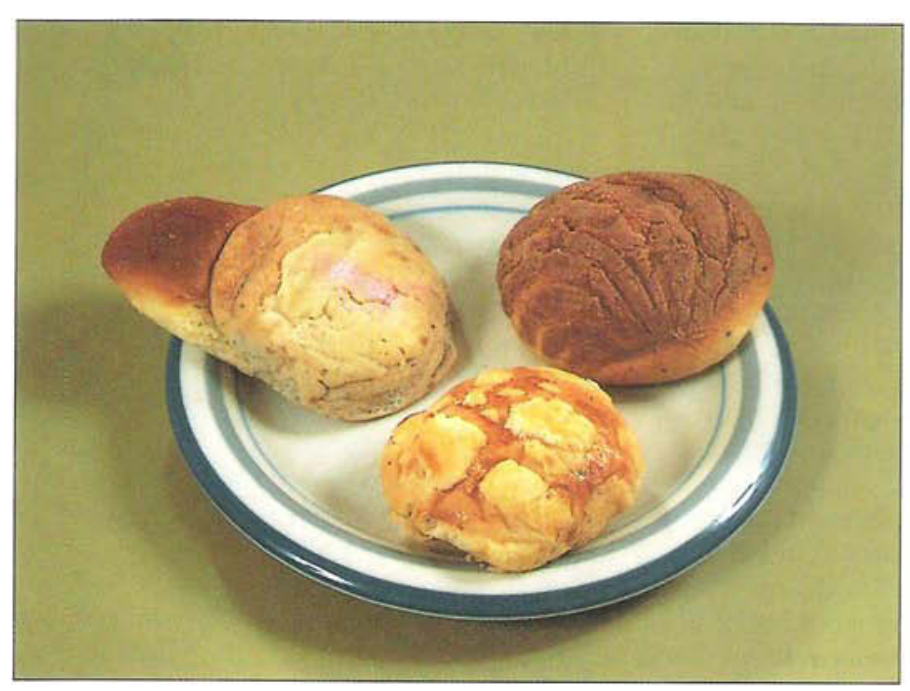

The traditional Mexican sweet bread, pan dulce, is lower in sugar and fat than most American pastries. It is usually eaten along with hot beverages, either at breakfast or at night.

them consumed it daily. Mexican immigrants strongly preferred whole milk; Mexican-Americans were more likely to choose low-fat milk.

There were significant changes in the way milk was consumed in the United States. Milk consumption in Mexico was mainly in the form of "atole" (a traditional hot milk-based beverage), "arroz con leche" (rice cooked with milk and sweetened with sugar), and coffee with milk. In the United States, most milk is consumed with ready-to-eat breakfast cereals. While only $8 \%$ of the immigrants consumed ready-to-eat cereals in Mexico, $78 \%$ consumed them in the United States. Readyto-eat breakfast cereals were eaten at breakfast and at the night meal, "cena," a traditional light dinner.

These breakfast cereals were eaten in place of native hot beverages, such as atole. This change can be considered negative from both economic and nutritional perspectives. Ready-to-eat breakfast cereals are much costlier than traditional breakfast foods. Even though ready-to-eat breakfast cereals are enriched with iron and vitamins, most are high in calories. Obesity is prevalent among Latino children and adults, and consumption of high-calorie breakfast cereals can contribute to increasing this health risk.

The dairy food showing the second largest increase in frequency of consumption was ice cream. Only $24 \%$ of the immigrants consumed ice cream in the core diet while living in Mexico. Although Mexican-Americans were more likely to consume low-fat milk, $46 \%$ consumed ice cream. The preference for whole milk among immigrants from Mexico may reflect the fact that in small Mexican towns and rural areas milk fat is often removed and water added to the milk to increase

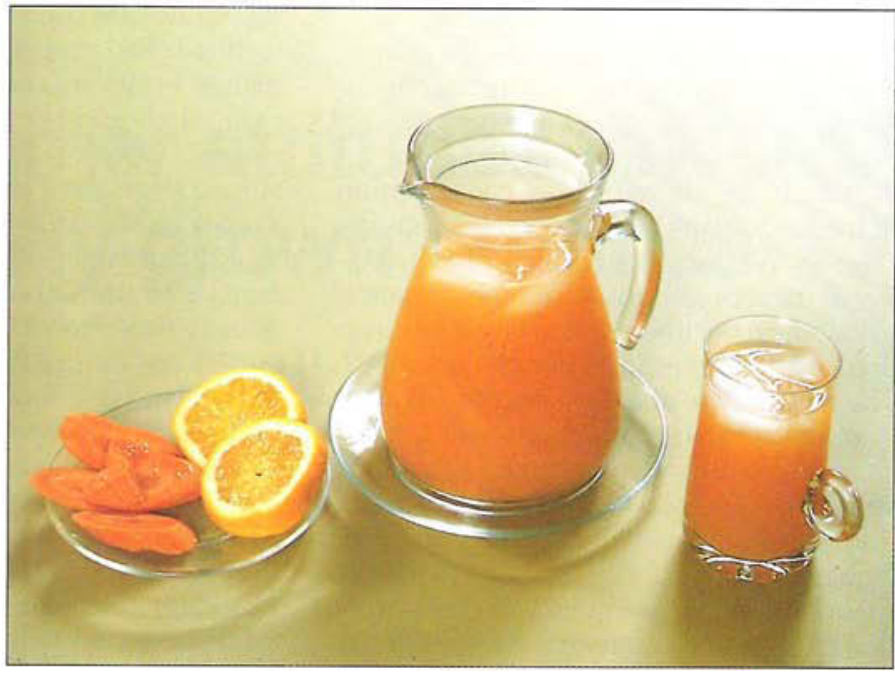

Fruit-flavored water drinks (aguas frescas), popular in Latin America, provide a low-cost alternative to highly sugared drinks. the milk's volume, and therefore the seller's profit. Health and nutrition educators who counsel Latinos about the benefits of low-fat milk should explain that in the United States, milk that is low in fat is nutritious, since it usually is enriched with calcium and other nutrients.

Tortilla and masa dishes. The consumption of corn tortillas has remained relatively stable over time. Ninety-eight percent of the immigrants consumed corn tortillas in the core diet while living in Mexico and after immigration to the United States. Consumption of corn tortillas by Mexican-Americans declined slightly: $84 \%$ reported consuming this food 2 to 7 days a week. Flour tortillas, almost unknown in Mexico (with the exception of Mexican states bordering the United States), emerged as almost a new food item after immigration here. Thus, although only $14 \%$ of the immigrants reported consuming flour tortillas in Mexico, $39 \%$ of the Mexican-Americans reported consuming flour tortillas 2 to 7 days a week. For some participants, flour tortillas are more convenient to use in bag lunches than corn tortillas, which break when cold and leak easily. Two traditional foods prepared with corn tortillas, tostadas and "chilaquiles," have almost disappeared from the core diet in the United States.

Beans, rice, and pasta. Consumption of beans and rice prepared with vegetables has decreased in the United States. For example, consumption of boiled beans ("frijoles a la olla") decreased from $84 \%$ in Mexico to $71 \%$ after immigration and $42 \%$ among Mexican-Americans. Similar decreases were observed for refried beans. Decreasing consumption of refried beans can be a positive way of decreasing fat intake. On the other hand, boiled beans are an excellent and inexpensive source of protein and fiber. Yet the frequency of consumption of boiled beans is decreasing even more quickly than that of refried beans.

Although the frequency of rice consumption remains about the same, there has been a significant change in the way rice is consumed. In Mexico, most respondents ate rice prepared with tomato, carrots, and other vegetables: "sopa de arroz." In the United States, however, consumption of sopa de arroz decreased, whereas consumption of plain cooked rice increased from 9\% (in Mexico) to 32\% (after immigration). The same figure (32\%) was reported by Mexican-Americans. Declining consumption of sopa de arroz is considered negative, since tomatoes and carrots are good sources of vitamin A and fiber.

Pasta consumption in the core diet decreased even more than rice or bean consumption. Of the sample, $68 \%$ reported consuming pasta soup in Mexico compared with $36 \%$ after immigration. Pasta appeared in the core diet of only $17 \%$ of the Mexican-Americans studied. "Sopa de fideo" (vermicelli prepared with tomato sauce) was consumed by $32 \%$ of the sample before immigration, by $20 \%$ after immigration, and by $10 \%$ of the MexicanAmericans. Decreased pasta consumption can also be viewed as a negative change, since pasta-based dishes are a source of vegetables. Pasta is also an inexpensive source of complex carbohydrates.

Meat and eggs. Meat as a combined category (beef, poultry, fish, etc.) was consumed in Mexico almost daily by $97 \%$ of the sample. Meat consumption remained high after immigration (91\%), and was equally high among Mexican-Americans $(92 \%)$. 
While the frequency of meat consumption did not change significanly, there were significant changes in the ways in which those meats were consumed. In Mexico, meats are almost always prepared with chilies, tomatoes, and other vegetables. In the United States, consumption of meats prepared with vegetables has decreased. While consumption of five traditional meat preparations (which contain vegetables) declined drastically, consumption of grilled meat and ham increased. The tendency to abandon traditional meatvegetable preparations may result in decreased consumption of chilies, carrots, verdolagas (purslane), and other nutritious vegetables usually included in meat dishes.

In the sample, frequency of consumption of eggs in the core diet declined from $82 \%$ in Mexico to $68 \%$ after immigration, and only $59 \%$ of the Mexican-Americans consumed eggs. This may reflect an increased awareness about the cholesterol content of eggs. One positive change was the decreased use of raw eggs in the beverage "licuado" (milk blended with fruits and, sometimes, raw egg). This reduces the risk of salmonella poisoning. Examples of traditional egg preparations that include vegetables are fried eggs topped with a tomato-based sauce and scrambled eggs with vegetables. These dishes decline in popularity after immigration. The decrease in egg consumption can be viewed as a healthy change for those with high levels of blood cholesterol. It can be viewed, however, as a negative change for some, since eggs are an inexpensive source of iron, protein, and vitamin $A$.

Breads and pastries. Breads commonly consumed in Mexico are "pan dulce" (sweet bread), "bolillo" (a white French roll), and, to a much lesser extent, sliced white bread. Although pan dulce is widely available in California in Mexican food stores and in major American chains in areas with large populations of MexicanAmericans, its consumption has declined greatly. While living in Mexico, $84 \%$ of the sample ate it 2 to 7 days a week; after immigration, $29 \%$ ate it. Only $15 \%$ of the Mexican-Americans consumed pan dulce in the core diet. Consumption of sliced white bread, on the other hand, increased from $15 \%$ in Mexico to $66 \%$ after immigration. Sliced white bread was consumed by $84 \%$ of the Mexican-Americans. Consumption of cookies increased in the United States. Consumption of cookies, part of the core diet for $25 \%$ of the sample in Mexico, soared to $61 \%$ after immigration; cookie consumption was slightly lower (52\%) among Mexican-Americans. Contrary to popular belief, consumption of American pastries, such as doughnuts, cakes, and pies, was below 6\% in Mexico and below $10 \%$ in the United States.
Vegetables and fruits. Traditionally, vegetables are used in soups, meat dishes, tortilla-based preparations, and other dishes. Fruits are consumed fresh and in fruit salads and juices. Although a high number $(80 \%)$ of the participants consumed vegetables and fruits at least twice a week in Mexico, consumption increased by $12 \%$ for vegetables and by $13 \%$ for fruits after immigration. Consumption frequency was almost the same for MexicanAmericans as for Mexican immigrants. As with other basic foods, however, many of the traditional ways in which vegetables and fruits are consumed decreased, and some tended to disappear from the core diet. Among the traditional vegetable preparations that tended to decrease significantly in the core diet were Mexican salsas prepared with green or red tomato.

At the same time, consumption of vegetable salad, which was low in Mexico ( $13 \%$ in the core diet), increased to $51 \%$ after immigration and to $74 \%$ among Mexican-Americans. A similar increase was observed for cooked vegetables as side dishes. The increased consumption of vegetables as salads and cooked side dishes cannot be viewed as an entirely healthy change, since these two relatively new ways to consume vegetables brought about consumption of additional fat in the form of salad dressing and margarine or butter. Furthermore, vegetables used in salads, such as lettuce and celery, are low in nutrients. Consumption of fruit salad and "aguas frescas de frutas" (fruit-based beverages), both common in Mexico, significantly decreased in the United States.

In Mexico, aguas frescas were consumed at least 2 days a week by $62 \%$ of the immigrants. Consumption decreased to $41 \%$ after immigration, and was only 17\% among Mexican-Americans. These traditional homemade beverages were replaced by commercially prepared drinks such as Kool-Aid, Tang, and other sugarrich drinks.

Fats. Use of lard decreased from $67 \%$ in Mexico to $28 \%$ after immigration. Use of lard was even lower among MexicanAmericans; only $12 \%$ of them used it in the core diet. Similarly, consumption of Mexican cream ("crema") significantly decreased, from $48 \%$ in Mexico to $14 \%$ after immigration. Only $1 \%$ of the MexicanAmericans consumed crema as part of the core diet. Although consumption of the two traditionally used fats decreased, other less traditional fats were added to the diet in this order: margarine and butter, salad dressing, mayonnaise, vegetable oil, and sour cream. As mentioned earlier, increased consumption of vegetable salad and cooked vegetables contributed to increased use of fat. This increase in fat consumption is the result of the incorporation of relatively new foods (i.e., sandwiches prepared with mayonnaise, margarine, butter, or peanut butter, and vegetable salads prepared with dressing) and to new ways of consuming traditional foods.

In summary, significant changes in the diet of the Latino population studied were found. The leading eight foods new to the diet were sliced white bread, margarine and butter, ready-to-eat breakfast cereals, vegetable salad, salad dressing, mayonnaise, oil, and Kool-Aid- and Tang-type beverages. In contrast, the leading eight traditional foods that have been withdrawn from diets include Mexican sweet bread, lard, soup of pasta, Mexican cream, boiled beans, water flavored with fruits, milk-based gruel, and tostadas.

\section{Conclusions}

Food patterns of the Latinos surveyed in California are evolving. Overall, healthy and less-healthy trends are evident in the primary core diet of Mexican immigrants and Mexican-Americans. Healthy changes include a moderate increase in the consumption of milk, vegetables, and fruits, and a large decrease in the consumption of lard and Mexican cream. However, these modest improvements should be viewed with caution. While consumption of vegetables has increased slightly, the introduction of salads and cooked vegetables has increased the use of fats - as salad dressings and as margarine or butter.

Other less-healthy changes include a severe decline in the consumption of traditional fruit-based beverages in favor of high-sugar drinks and other sugar-rich foods. Inexpensive sources of complex carbohydrates, such as beans, rice, and pasta, also have decreased as a result of acculturation in the United States. In addition to the possible impact on the health of the group studied, these dietary changes may also affect the economy of the family as low-priced foods are replaced with moreexpensive ones.

Health and nutrition educators, growers, and food retailers should support and stimulate the preservation of healthy traditional food practices among Latino consumers. In addition, alternatives to high consumption of fats and sugars should be encouraged.

E. Romero-Gwynn is Extension Nutrition Specialist and D. Gwynn is Research Sociologist, Department of Nutrition, UC Davis; $B$. Turner, G. Stanford, E. West, and E. Williamson are Cooperative Extension Home Economists in the counties of Los Angeles, San Diego, Santa Clara, and Riverside, respectively; L. Grivetti is Professor and $R$. McDonald is Assistant Professor, Department of Nutrition, UC Davis.

This study was funded by the California Expanded Food and Nutrition Education Program (EFNEP). 